\title{
Concussion symptoms in youth motocross riders: a prospective, observational study
}

\author{
${ }^{*}$ T. David Luo, MD, ${ }^{1}$ Michelle J. Clarke, MD, ${ }^{2}$ Amy K. Zimmerman, MD, ${ }^{1}$ \\ Michael Quinn, CRNA, MNA, ${ }^{3}$ David J. Daniels, MD, PhD, ${ }^{2}$ and Amy L. McIntosh, MD ${ }^{1}$
}

Departments of ${ }^{1}$ Orthopedic Surgery, ${ }^{2}$ Neurosurgery, and ${ }^{3}$ Anesthesia, Mayo Clinic College of Medicine, Mayo Clinic, Rochester, Minnesota

\begin{abstract}
OBJECT Action motorsports, including motocross, have been gaining popularity among children and adolescents, raising concerns for increased risk of concussions in participating youth. The authors undertook this study to test the following hypotheses: 1) that there is a high rate of concussion symptoms associated with a number of preventable or adjustable risk factors, and 2) that a high percentage of these symptoms are not be reported to adults and medical personnel.

METHODS The authors identified all motocross riders under the age of 18 at a regional racetrack during the riding season between May and October 2010. The participants completed questionnaires pertaining to demographic characteristics and variables associated with motocross. The questionnaire results were compared with the incidence of selfreported concussion symptoms.
\end{abstract}

RESULTS Two hundred two riders were identified who met the criteria for participation in the study, and 139 of them completed the study questionnaire. Of these 139 riders, 67 (48\%) reported at least 1 concussion symptom during the season. The majority of riders (98\%) reported "always" wearing a helmet, and $72 \%$ received professional help with fitting of their helmets. Proper helmet fitting was associated with a $41 \%$ decreased risk of concussion symptoms (RR 0.59, 95\% $\mathrm{Cl} 0.44-0.81, p<0.01)$. Sixty-six riders $(47 \%)$ reported having received sponsor support for motocross participation. Sponsor support conferred a relative risk for concussion symptoms of $1.48(95 \% \mathrm{Cl} 1.05-2.08, \mathrm{p}=0.02)$.

CONCLUSIONS Nearly half of all motocross competitors under the age of 18 reported concussion symptoms. Preventive measures are necessary to limit the negative impact from concussions. The risk of concussive injury can be decreased for pediatric motocross riders if they receive professional help with proper helmet fitting and through implementation of stricter guidelines regarding sponsorship.

http://thejns.org/doi/abs/10.3171/2014.11.PEDS14127

KEY WORDS concussion; symptoms; motocross; pediatric; return to play; trauma

A CTION motorsports, including motocross, have been popular since the middle of the 20th century and are gaining popularity among children and adolescents. ${ }^{2,10,18}$ Motocross is a nationally organized sport that involves riding 2-wheeled motorized bikes around enclosed outdoor tracks over rough terrain and various obstacles. Youth motocross riders compete in age-based groups beginning at ages as young as 4 years. ${ }^{18}$ Motocross is a physically demanding sport, as riders need to maintain balance and control to navigate sharp turns and jump over obstacles. As participation increases, so does the number of youth at risk for sport-related injuries. The high speeds, challenging obstacles, and intense physical and mental demands all contribute to the sport's inherent risk of injury. ${ }^{16}$ Little information exists in the medical literature about motocross participation or injuries, with even less pertaining to pediatric participants. ${ }^{6,7}$ Relatively lower participation rates compared with mainstream youth athletics, 
lack of scholastic athletic infrastructure, and associated injury surveillance capacity contribute to this paucity of data. ${ }^{1,8,13,16}$

Epidemiological data are necessary in order to counsel youth and families about participation and effectively target injury prevention efforts. A previous retrospective review of motocross injuries treated at our institution from 2000 to 2007 identified 299 motocross injuries in 249 unique pediatric patients. ${ }^{18}$ Of these 299 injury episodes, 141 (47\%) required hospital admission, consistent with prior studies that show 20 to 30 admissions annually from motorbike injuries. Furthermore, 19 patients $(6 \%)$ required admission to an intensive care unit, and $91(30 \%)$ required surgical interventions (89\% of which were orthopedic in nature). Head trauma with loss of consciousness was reported in $18 \%$ of cases.

Concussive brain injury (CBI) is a condition that merits special attention due to its prevalence, difficulty in diagnosis, and significant consequences for young athletes. CBI is defined by the American Academy of Neurology as change in mental status induced by trauma that may or may not be associated with loss of consciousness. ${ }^{10,17,20}$ Key features include confusion, memory loss, and delayed information processing. Data show only a small percentage $(<10 \%)$ of youth sports concussions involve loss of consciousness. ${ }^{9,13}$ The difficulty in diagnosis, the lack of diagnostic criteria consensus, and the eagerness of young athletes to return to sports participation likely lead to an underestimation of concussion symptom recognition in youth motocross athletes. ${ }^{12}$ Previous studies suggest that the presence of certain symptoms is highly suggestive of a concussion. The diagnostic criteria/symptoms include: headache, nausea or vomiting, dizziness or poor balance, blurry or double vision, photophobia, feeling hazy or foggy, poor concentration, memory problems, and irritability. ${ }^{12,24}$ Concussions in adolescents require more time for recovery and can negatively impact academic performance, social development, and future ability to participate in athletics. ${ }^{9}, 12,14,17,21$ Impairments in knowledge and skill acquisition subsequent to CBIs are particularly destructive for youth who are constantly charged with learning and demonstrating competence..$^{21}$ Long-term neurological complications are concerning but not well understood due to a lack of prospective studies. ${ }^{13}$

The purpose of this study is to evaluate concussion symptoms in pediatric motocross participants over the course of a season and to identify risk factors associated with those symptoms. We hypothesized that there would be a high rate of CBIs associated with a number of preventable or adjustable risk factors. Based on data from other pediatric sports in which contact or collision may be purposeful, incidental, or accidental, we further hypothesized that a high percentage of CBIs would not be reported to adults and medical personnel.

\section{Methods}

We identified and contacted all motocross riders under the age of 18 at one of the region's most popular racetracks (Spring Creek Motocross Park) during the riding season between May and October 2010. Institutional review board approval was obtained for all aspects of the study. Informed consent and assent was obtained from all riders and their parents who agreed to participate in the study. The participants completed the same questionnaire, with parental assistance as needed, on 3 separate occasions during the study period (in May, July, and October of 2010). Survey questions included demographic variables (age, sex, and racing classes), years of recreational and competitive participation, amount and intensity of training and practice, number and frequency of concussive episodes, type and usage of protective equipment, sponsor support for motocross participation, presence and frequency of concussion symptoms, medical evaluation of concussion symptoms, recovery time after symptomatic episodes, presence of chronic or lingering symptoms, and rider and parental attitudes toward the sport.

The self-reported concussion symptoms in our survey were based on a set of definitions widely accepted by clinicians to be highly suggestive of the presence of a concussion. The criteria include headache, nausea or vomiting, dizziness or poor balance, blurry or double vision, photophobia, feeling hazy or foggy, poor concentration, memory problems, and irritability.9,16 Statistical analysis was performed using Pearson's chi-square test and the two-tailed Fisher's exact test; $p$ values less than 0.05 were considered to indicate statistical significance. Descriptive statistics were reported as numeric values (percentage, mean, median, range, and/or standard deviation), and estimates of risk were presented with $95 \%$ confidence intervals.

\section{Results}

\section{Demographic Characteristics}

During the study period, we identified 202 riders under the age of 18 . Of these, 139 riders $(69 \%)$ with a mean age of 12.2 years (range 5-17 years) agreed to participate in the study and completed the surveys. Riders under the age of 14 were allowed parental assistance in completing the survey. The group included 127 male riders (91\%) and 12 female riders (9\%). Fifty-four riders (39\%) were under 12 years of age, and $85(61 \%)$ were between 12 and 17 years of age. The majority of respondents had been riding recreationally for $4-5$ years $(26 \%)$ and participating in organized races for $2-3$ years $(31 \%)$.

\section{Concussive Injuries}

Based on the criteria we provided to the participants, 67 youth riders $(48 \%)$ reported experiencing at least 1

TABLE 1. Concussive symptoms reported during a single season by 67 motocross riders under 18 years of age

\begin{tabular}{lc}
\hline \multicolumn{1}{c}{ Symptoms } & No. of Riders $(\%)$ \\
\hline Headache & $42(63)$ \\
\hline Feeling hazy/foggy & $37(55)$ \\
\hline Dizziness/poor balance & $32(48)$ \\
\hline Memory/concentration problems & $27(40)$ \\
\hline Blurry/double vision & $21(31)$ \\
\hline Photophobia & $21(31)$ \\
\hline Nausea/vomiting & $19(28)$ \\
\hline
\end{tabular}


concussion symptom from riding or racing during the motocross season (Table 1). These riders had an average of 1.37 concussive episodes during the study period (range $1-5$ episodes). Of the 67 riders with concussion symptoms, $41(61 \%)$ continued racing the same day, although 25 did subsequently suspend participation for a portion of the remaining season. Overall, 16 (24\%) of the riders with concussive symptoms did continue to actively participate for the duration of the motocross season. The 51 riders $(76 \%)$ who chose to suspend participation were away from the sport for a mean of 2.7 weeks (range 0-36 weeks, median 1 week). Fifty-two riders (78\%) sought treatment from a health care professional for their symptoms. Multiple episodes of concussion symptoms during the season from any source (i.e., not just motocross) were reported by 46 riders $(33 \%)$.

Of the 139 surveyed participants, 33 (24\%) riders reported chronic headaches that first started after falls or crashes involving impact between their helmets and the ground during that season. The associated motocross activities that induced the headaches are described in Table 2.

\section{Protective Equipment}

Of the 139 youth riders surveyed, $136(98 \%)$ reported "always" wearing a helmet while riding their motorbike, while $2(1 \%)$ reported "mostly" wearing their helmet. Of the 138 riders who reported always wearing a helmet, 100 (72\%) received help from experts at motocross-specific shops with proper fitting of their helmets prior to purchase (Table 3 ). Ten riders (7\%) reported wearing a mouth guard while riding, and 112 riders (81\%) wore rigid neck braces designed to disperse forces generated during crashes or hard landings and to prevent excessive cervical spine motion. The use of mouth guards and rigid neck braces did not significantly correlate with decreased risk of developing concussion symptoms. Receiving help from a motocross shop/store expert with fitting a helmet prior to purchase was associated with a $41 \%$ decreased risk of reporting concussion symptoms (RR 0.59, 95\% CI 0.44-0.81, p < 0.01).

\section{Sponsor Support}

Sixty-six riders (47\%) reported having received sponsor support for motocross participation. Of those, 51 (77\%) received shop support, $9(14 \%)$ received factory support, and $4(6 \%)$ received both factory and shop support. Sponsor support conferred a relative risk of 1.48 (95\% CI $1.05-$ $2.08)$ for concussion symptoms $(\mathrm{p}=0.02)$.

TABLE 2. Chronic headaches and associated activities in 139 youth motocross riders

\begin{tabular}{lc}
\hline \multicolumn{1}{c}{ Activity } & No. of Riders (\%) \\
\hline Any physical activity & $42(30)$ \\
\hline Motocross practice & $30(22)$ \\
\hline Motocross racing/competition & $29(21)$ \\
\hline Riding-related falls & $46(33)$ \\
\hline Hitting big bumps on the track & $17(12)$ \\
\hline Landing jumps & $11(8)$ \\
\hline
\end{tabular}

TABLE 3. Fit and design characteristics of helmets used by 138 youth motocross riders

\begin{tabular}{lc}
\hline \multicolumn{1}{c}{ Characteristic } & No. of Riders (\%) \\
\hline Adult-sized helmet & $93(67 \%)$ \\
\hline Youth-sized helmet & $36(26 \%)$ \\
\hline Unsure of helmet size & $9(7 \%)$ \\
\hline Snug-fitting helmet & $116(84 \%)$ \\
\hline Tight-fitting helmet & $11(8 \%)$ \\
\hline Slightly loose helmet & $11(8 \%)$ \\
\hline Full face shield & $118(86 \%)$ \\
\hline Open-face helmet & $18(13 \%)$ \\
\hline Ejection system to facilitate removal & $28(20 \%)$ \\
\hline Currently using a helmet that has previously & $74(54 \%)$ \\
\hline impacted the ground during a crash & \\
\hline
\end{tabular}

\section{Rider and Parental Attitude Toward Motocross}

When asked to describe their riding style, 20 riders (14\%) identified themselves as "conservative" riders who prefer learning and practicing techniques before increasing their speed; 48 (35\%) reported "some risk-taking"; $52(37 \%)$ were "aggressive" and felt more willing to take chances; 19 (14\%) were "highly aggressive." No significant association was found between self-reported riding style and endorsement of concussion symptoms. There were, however, 103 riders (74\%) who reported incidents of crashes related to aggressive riding or racing. This was associated with a relative risk of 1.79 (95\% CI 1.04-3.07) for concussion symptoms $(p=0.02)$. Youth riders reported their parents' feelings toward their motocross participation as follows: 1 parent $(<1 \%)$ "did not approve"; 13 (9\%) were "neutral"; 85 (61\%) were "approving"; 40 (29\%) were "highly encouraging." No significant association was found between parental attitudes toward the sport and endorsement of concussion symptoms.

\section{Risks for Concussion Symptoms}

Table 4 summarizes the relative risk and confidence intervals of factors that were significantly associated with concussion symptoms in youth motocross riders. Self-reported aggressive driving and sponsor support were associated with an increased risk of experiencing concussion symptoms. Receiving professional help with helmet fit decreased the risk of developing concussion symptoms.

\section{Discussion}

Our study found a high rate of CBIs in children participating in organized motocross over the course of one

TABLE 4. Factors associated with concussion symptoms

\begin{tabular}{lccc}
\hline \multicolumn{1}{c}{ Factor } & $\mathrm{RR}$ & $95 \% \mathrm{Cl}$ & $\mathrm{p}$ Value \\
\hline Receiving help w/ helmet fitting & 0.59 & $0.44-0.81$ & $<0.01$ \\
\hline Self-reported aggressive driving & 1.79 & $1.04-3.07$ & 0.02 \\
\hline Sponsor support & 1.48 & $1.05-2.08$ & 0.02 \\
\hline RR $=$ relotive risk & & &
\end{tabular}


season. Nearly $50 \%$ of the pediatric and adolescent motocross riders reported concussion symptoms during the outdoor 2010 racing season at a selected race track. Surveyed riders reported an average of 1.37 concussive episodes, with $33 \%$ of riders reporting repetitive head injuries during the study period. It was encouraging to see that the majority of riders who reported concussion symptoms (78\%) sought medical treatment; however, most of them either continued to race or only briefly suspended participation (mean 2.7 weeks). In 33 of these riders, the acute injuries led to chronic headaches exacerbated by continuous participation in motocross. We feel that the reported concussion symptoms are related to crashes, as opposed to activity-related motion such as engine vibration or riding over rough terrain.

It is difficult to compare our findings to the existing literature, as there is a paucity of data on head injuries in pediatric motocross participants. Larson et al..$^{18}$ reported loss of consciousness in $18 \%$ of all documented motocross injuries. These data were obtained from patient registries, meaning that participants with less recognizable or reportable symptoms of CBIs on the racetrack may not have presented to the hospital or emergency room. In general, there is lack of consensus over the minimum criteria for reporting concussive injury; thus concussion symptoms are thought to be underreported in all sports and levels of competition. ${ }^{12,21,24}$ The most commonly reported symptom of a concussion is headache, although other symptoms may be present concomitantly. ${ }^{10,13}$ Loss of consciousness is often misconstrued by medical personnel as necessary for a diagnosis of concussion, although loss of consciousness is less common than confusion or amnesia after any traumatic head injury. ${ }^{12,13,17}$ Motocross riders often present with subtle signs and symptoms of concussion. Those with clear signs and symptoms may minimize them, thinking that they are a normal part of the sport or related to heat illness/exhaustion.

The main weakness of this study is that all of the data were self-reported, and self-reported data have been shown to be unreliable as an indicator for concussions. ${ }^{26}$ Additionally, we feel that the self-reported nature of the survey likely leads to an underreporting bias, as both the $31 \%$ of riders not participating and the riders participating may have underreported symptoms for fear of having restrictions placed on themselves or their sport or because of a culture of toughness and concern about appearing weak in the eyes of their peers. Such underreporting has been noted in the collegiate cohort, with $43 \%$ of concussed student athletes knowingly hiding symptoms and a further $22 \%$ indicating that they would do so in the future. ${ }^{27}$ The lack of objective findings may not accurately represent the rate of concussion symptoms. Alternatively, the survey might have led to overreporting of symptoms. We think this to be unlikely, however, given good evidence for underreporting of head injuries in other collision sports. ${ }^{9,11,12}$

Clearly, the results of this survey demonstrate an inconsistent or nonexistent formal assessment of traumatic brain injury following a crash and a lack of consistent return-to-play guideline application. At the highest levels of the sport, concussion awareness is improving: American Motorcyclist Association Pro Racing, the premiere motorsport racing body, insists on concussion training and a baseline ImPACT (Immediate Postconcussion Assessment and Cognitive Testing) test prior to granting a license and passing a subsequent ImPACT test prior to resuming competition after concussion. ${ }^{23}$ These requirements apply to racers as young as 12 who qualify at a national level, but none of the riders in our study cohort met that criterion, and thus none were subject to these requirements. The ImPACT test is a validated computerized assessment system that has been adopted by professional sports leagues such as WWE (World Wrestling Entertainment), NFL (National Football League), NHL (National Hockey League), and MLB (Major League Baseball) (https://www.impacttest. com). Its global adoption as a tool, however, is hampered by cost. It is also notable that our study occurred in Minnesota, which has a "Concussion Law" that mandates that all coaches involved in a youth athletic activity that charges a fee implement concussion education including safe returnto-play guidelines. ${ }^{22}$ The number of athletes returning to motorsport racing following a concussive episode despite this law may be because athletes in motorsports may not have an identifiable or responsible coach. This underscores the need for grassroots education of parents and athletes.

Multiple efforts need to be undertaken to improve concussion identification and management. As the most frequent responsible supervisors, parents must be given information about recognizing the signs and symptoms of concussion. On-site emergency medicine personnel, sports medicine practitioners, and race referees can serve as the necessary resources to help decrease underreporting of concussions. ${ }^{21}$ Riders also need to understand the importance of refraining from racing while symptomatic to avoid "second-impact syndrome," which may have devastating effects in adolescent patients, including brain herniation and even death., ${ }^{9,15,25,26}$ Almost all reported cases of second-impact syndrome have occurred in adolescents, ${ }^{3,19}$ and persistent headache is frequently noted prior to the catastrophic second injury, ${ }^{4,5}$ potentially indicating ongoing neurophysiological pathology. ${ }^{28}$ Although second-impact syndrome is controversial, it is now accepted that athletes should be clinically asymptomatic and cognitively normal before return to play. ${ }^{28}$ Furthermore, even when they become symptom free, young athletes may continue to have neurocognitive deficits of which they are not aware. ${ }^{26}$ Cognitive rest, in addition to physical rest, has been suggested as a new part of the management of concussions in pediatric patients. The 4th International Conference on Concussion in Sport $^{20}$ and the American Academy of Pediatrics ${ }^{13}$ recommend modified school days or a temporary leave of absence, decreased academic workloads, and increased time to finish assignments or tests.

The reporting on the usage of safety equipment sheds light on current trends in pediatric motocross competitors. Most of the riders (98\%) always wore a helmet. The high rate of concussion symptoms despite the prevalent helmet use means simply wearing a helmet is not enough. It is of interest to note that receiving professional help with proper fitting of helmets corresponded with a $41 \%$ decrease in reported concussion symptoms. While "professional fitting" may overstate the nature of support garnered from a motorcycle shop employee, an understanding 
of equipment options, features, and experience in fitting multiple riders is likely an advantage. Previous research on this topic by Olvey et al. (unpublished data presented at Motorsports Engineering Conference \& Exposition 2006) provided recommendations on standards for helmet design in children aged 6-17 years. The recommendations include striving for helmets that are light, provide adequate levels of impact protection, are properly fitted with integrated padding and tightly fastened double chin strap, and are reasonably priced to promote use. We encourage youth motocross riders and their parents to purchase helmets that are made properly, in accordance with the above recommendations, and to seek assistance with helmet fit prior to purchase.

The increased relative risk of concussion symptoms associated with sponsor support and aggressive riding in this series is also significant and concerning. Likely, aggressive riding and sponsorship are linked. Perhaps consideration for sponsorship should include baseline race-accident statistics and technical skills assessments to promote safe riding habits to decrease frequency and degree of accidents that could cause concussions.

Links between sponsorship, aggressiveness of riding style, helmet fitting, degree of impact, and concussive symptoms need further study. Along with the ImPACT test, the use of accelerometers in racing and training situations may prove effective. One device, the Reebok Checklight (http://www.mc10inc.com/consumer-products/sports/ checklight/), may help bridge the gap by encouraging concussion awareness, making medical evaluation enforceable, and by aiding the study of frequency and severity of impact and its sequelae. A skull cap is worn under the helmet, and impact severity is visibly displayed with a system of green, yellow, and red lights. Riders are encouraged to seek medical attention following yellow- and red-light crashes. Regardless of the system used, more studies are needed to fully understand the issues surrounding motocross racing and head injury in the pediatric population.

\section{Conclusions}

Nearly half of all motocross competitors under the age of 18 had concussion symptoms, based on self-report. Although $78 \%$ of these riders sought medical treatment for their symptoms, the majority either continued racing or returned too quickly to motocross. Almost all of the riders wore helmets, but this alone was not enough to prevent concussion symptoms after collisions. We encourage all youth motocross riders to wear properly fitted helmets and to refrain from early return to physical activity after experiencing concussion symptoms. We also encourage medical professionals managing concussion symptoms in this age population to follow progressive return-to-ride/play recommendations set forth by the International Conference on Concussion in Sport and the American Academy of Pediatrics. Adherence to state laws and recommendations should also be considered when returning any athlete to sport after concussion symptoms have cleared.

\section{References}

1. Abernethy L, Bleakley C: Strategies to prevent injury in adolescent sport: a systematic review. Br J Sports Med 41:627-638, 2007

2. American Academy of Pediatrics Committee on Accident and Poison Prevention: All-terrain vehicles: two-, three-, and four-wheeled unlicensed motorized vehicles. Pediatrics 79:306-308, 1987

3. Bruce DA, Alavi A, Bilaniuk L, Dolinskas C, Obrist W, Uzzell B: Diffuse cerebral swelling following head injuries in children: the syndrome of "malignant brain edema." J Neurosurg 54:170-178, 1981

4. Cantu RC: Recurrent athletic head injury: risks and when to retire. Clin Sports Med 22:593-603, x, 2003

5. Cantu RC: Second-impact syndrome. Clin Sports Med 17:37-44, 1998

6. Daniels DJ, Clark MJ, Puffer R, Luo TD, McIntosh AL, Wetjen NM: High occurrence of head and spine injuries in the pediatric population following motocross accidents. J Neurosurg Pediatr [epub ahead of print January 2, 2015. DOI: 10.3171/2014.9.PEDS14149]

7. Daniels DJ, Luo TD, Puffer R, McIntosh AL, Larson AN, Wetjen NM, et al: Degenerative changes in adolescent spines: a comparison of motocross racers and age-matched controls. J Neurosurg Pediatr [epub ahead of print January 2, 2015. DOI: 10.3171/2014.9.PEDS14153]

8. Emery CA: Risk factors for injury in child and adolescent sport: a systematic review of the literature. Clin J Sport Med 13:256-268, 2003

9. Grace MT: Concussion in the pediatric patient. J Pediatr Health Care 27:377-384, 2013

10. Grange JT, Bodnar JA, Corbett SW: Motocross medicine. Curr Sports Med Rep 8:125-130, 2009

11. Grindel SH, Lovell MR, Collins MW: The assessment of sport-related concussion: the evidence behind neuropsychological testing and management. Clin J Sport Med 11:134143,2001

12. Guskiewicz KM, Valovich McLeod TC: Pediatric sportsrelated concussion. PM R 3:353-364, 2011

13. Halstead ME, Walter KD, Council on Sports Medicine and Fitness: Clinical report-sport-related concussion in children and adolescents. Pediatrics 126:597-615, 2010

14. Karlin AM: Concussion in the pediatric and adolescent population: "different population, different concerns." PM R 3 (10 Suppl 2):S369-S379, 2011

15. Kelly JP, Nichols JS, Filley CM, Lillehei KO, Rubinstein D, Kleinschmidt-DeMasters BK: Concussion in sports. Guidelines for the prevention of catastrophic outcome. JAMA 266:2867-2869, 1991

16. Kennedy RD, Potter DD, Osborn JB, Zietlow S, Zarroug AE, Moir CR, et al: Childhood motocross truncal injuries: highvelocity, focal force to the chest and abdomen. BMJ Open 2:e001848, 2012

17. Kirkwood MW, Yeates KO, Wilson PE: Pediatric sportrelated concussion: a review of the clinical management of an oft-neglected population. Pediatrics 117:1359-1371, 2006

18. Larson AN, Stans AA, Shaughnessy WJ, Dekutoski MB, Quinn MJ, McIntosh AL: Motocross morbidity: economic cost and injury distribution in children. J Pediatr Orthop 29:847-850, 2009

19. McCrory P: Does second impact syndrome exist? Clin J Sport Med 11:144-149, 2001

20. McCrory P, Meeuwisse WH, Aubry M, Cantu B, Dvorák J, Echemendia RJ, et al: Consensus statement on concussion in sport: the 4th International Conference on Concussion in Sport held in Zurich, November 2012. Br J Sports Med 47:250-258, 2013

21. Meehan WP III, Taylor AM, Proctor M: The pediatric athlete: younger athletes with sport-related concussion. Clin Sports Med 30:133-144, x, 2011

22. Minnesota Youth Athletic Services: Minnesota 
Concussion Law. (http://www.myas.org/gm/sport. asp?NewsID=1635\&SportID=17) [Accessed November 23, 2014]

23. MX Sports Pro Racing: Competition Bulletin 2014-1: ImPACT Baseline Testing for 2014. (http://www.mxsportspro racing.com/articles/2186_competition-bulletin-2014-1-impactbaseline-test-for-2014) [Accessed November 23, 2014]

24. Patel DR, Reddy V: Sport-related concussion in adolescents. Pediatr Clin North Am 57:649-670, 2010

25. Saunders RL, Harbaugh RE: The second impact in catastrophic contact-sports head trauma. JAMA 252:538-539, 1984

26. Schatz P, Moser RS: Current issues in pediatric sports concussion. Clin Neuropsychol 25:1042-1057, 2011

27. Torres DM, Galetta KM, Phillips HW, Dziemianowicz EM, Wilson JA, Dorman ES, et al: Sports-related concussion: anonymous survey of a collegiate cohort. Neurol Clin Pract 3:279-287, 2013

28. Weinstein E, Turner M, Kuzma BB, Feuer H: Second impact syndrome in football: new imaging and insights into a rare and devastating condition. J Neurosurg Pediatr 11:331-334, 2013

\section{Author Contributions}

Conception and design: Luo, Zimmerman, Quinn, McIntosh. Acquisition of data: Luo, Zimmerman, Quinn. Analysis and interpretation of data: Luo, Zimmerman. Drafting the article: Clarke, Luo. Critically revising the article: Clarke, Luo, Quinn, Daniels, McIntosh. Reviewed submitted version of manuscript: Clarke, Luo, Quinn, Daniels, McIntosh. Approved the final version of the manuscript on behalf of all authors: Clarke. Statistical analysis: Luo. Study supervision: McIntosh.

\section{Correspondence}

Michelle J. Clarke, Mayo Clinic, Department of Neurologic Surgery, 200 1st St. SW, Rochester, MN 55905. email: clarke. michelle@mayo.edu. 